\title{
Seismic Capacity Test of Overhead Crane under Horizontal and Vertical Excitation - Element Model Test Results on Nonlinear Response Behavior-
}

\author{
Kenichi Suzuki ${ }^{\mathrm{a}}$, Masakatsu Inagaki ${ }^{\mathrm{a}}$, Shirou Fukunishi ${ }^{\mathrm{a}}$, \\ Tadashi Iijima $^{\mathrm{b}}$, and Takashi Matsumoto ${ }^{\mathrm{c}}$ \\ ${ }^{a}$ Seismic Safety Division, Japan Nuclear Energy Safety Organization, Kamiya-cho MT \\ Bldg., 4-3-20, Toranomon, Minato-ku, Tokyo, Japan, suzuki-kenichi1@jnes.go.jp \\ ${ }^{b}$ Mechanical Engineering Research Laboratory, Hitachi, Ltd., 832-2, Horiguchi, Hitachinaka, \\ Ibaraki, Japan, tadashi.iijima.ff@hitachi.com \\ ${ }^{c}$ Plant Design Section, Hitachi-GE Nuclear Energy, Ltd., 1-1, Saiwai-cho, 3-chome, \\ Hitachi, Ibaraki, Japan, takashi.matsumoto.xy@hitachi.com
}

Keywords: Overhead crane, Vertical excitation, Seismic capacity, Nonlinear behaviour, Shake table test, Simulation

\section{ABSTRACT}

The seismic capacity regarding the structural strength and operative function of equipment has been an important issue for seismic safety assessments of nuclear power plants. Since the new safety review guidelines for seismic design of nuclear power plants in Japan require dynamic analysis for vertical excitation, it has become an important issue to confirm the seismic capacity of equipment under vertical excitation.

An overhead crane used in a boiling-water nuclear reactor building is a typical piece of equipment with low rigidity, and resulting in vertical response amplification. A strong earthquake might cause nonlinear behaviour such as a slip, or leap and the resulting landing of the overhead crane, which may result in it derailing from the track. Accordingly, the Japan Nuclear Energy Safety Organization initiated a seismic test program in fiscal year 2006. The program included two test series for investigating nonlinear behaviour, structural strength, and validity of the structural retrofit against vertical excitation. The first test series was a preliminary element model test, and focused on certain issues concerning nonlinear behaviour under vertical excitation. The second test series was a shake table test of a 1/2.5-scale model with the same structure as an actual crane. We summarized the former element model test and the simulation results.

\section{INTRODUCTION}

The seismic capacity regarding the structural strength and operative function of equipment has been an important issue for seismic safety assessments of nuclear power plants. The Nuclear Safety Commission of Japan (2006) revised the safety review guidelines for the seismic design of nuclear power plants in Japan to improve their seismic reliability. Since the guidelines require dynamic analysis for vertical excitation, it has become an important issue to confirm the seismic capacity of equipment under this type of excitation.

An overhead crane used in a boiling-water nuclear reactor (BWR) building is a typical piece of equipment with low rigidity, resulting in vertical response amplification. A strong earthquake might cause nonlinear behaviour, such as a slip, or leap and the resulting landing of the overhead crane, which may result in its derailing from a track. Komori et al. (1989) conducted a shake table test of 1/10-scale model to investigate the slip behaviour under horizontal excitation. Otani et al (1999) also conducted a shake table test of 1/8-scale model to investigate the leap behaviour under vertical excitation. They focused on the leap of the entire crane, and the trolley, therefore, was connected to girders to constrain the trolley. Simulation analyses were also performed, and the results were verified against the test results.

The Japan Nuclear Energy Safety Organization (JNES) initiated a seismic test program in fiscal year 2006 to address the issues of overhead cranes under vertical excitation. The program included two test series for investigating nonlinear behaviour and structural strength, and to validate the structural retrofit against vertical excitation. The first test series was a preliminary element model test, which focused on issues of the 
nonlinear behaviour under vertical excitation. The second test series was a 1/2.5-scale model test using the world's largest shake table at the National Research Institute for Earth Science and Disaster Prevention in Japan (E-Defense of NIED). The scale model had the same structure as an actual crane. JNES conducted the shake table test using this model, and investigated the nonlinear behaviour, structural strength and validity of the structural retrofit.

The element model test was composed of three types of tests. The first was a shake table test, which focused on the leap behaviour of a trolley mounted on flexible girders sliding on rails. The effect of the trolley's location on the girders was investigated in this test. The second was also a shake table test, which focused on the leap behaviour of a trolley, girders, carrying weight, and their interaction. The last was an impact test, which focused on the rebounding characteristics of the wheel system, which was applied to numerical analyses. Numerical analyses were also performed to simulate the nonlinear behaviour in the first two element model tests.

\section{TEST PROGRAM}

JNES conducted two test series for an overhead crane, as listed in Table 1 . The first was a preliminary element model test conducted in fiscal year 2007, which was composed of three types of tests. The second was a 1/2.5-scale model test at the E-Defense of NIED conducted in fiscal year 2008.

The element model test reported in this paper composed of the three types of tests using the model conditions listed in Table 2. The first was a shake table test of a 1/10-scale model subjected to horizontal and vertical excitation. The test focused on the leap of a trolley mounted on flexible girders sliding on rails. The effect of the trolley's location on the girders was investigated. The second was a shake table test of a 1/10scale model subjected to only vertical excitation. The test focused on leap behaviour with a carrying weight suspended from the trolley. The last was an impact test to obtain coefficients of restitution between a wheel and the rail using pendulum-type equipment.

Table 1. JNES test program

\begin{tabular}{lllll}
\hline Test series & \multicolumn{1}{c}{$\begin{array}{l}\text { Scale } \\
\text { (Girder length) }\end{array}$} & Test type & Schedule \\
\hline \multirow{2}{*}{ Element model test } & Test 1 & $1 / 10(4.6 \mathrm{~m})$ & $\begin{array}{l}\text { Shake table test } \\
(\text { Table size }: 6 \mathrm{~m} \times 4 \mathrm{~m})\end{array}$ & FY2007 \\
\cline { 2 - 5 } & Test 2 & $1 / 10(4.6 \mathrm{~m})$ & $\begin{array}{l}\text { Shake table test } \\
(\text { Table size }: 6 \mathrm{~m} \times 4 \mathrm{~m})\end{array}$ & FY2007 \\
\cline { 2 - 5 } & Test 3 & $-(-)$ & Impact test & FY2007 \\
\hline 1/2.5-scale model test & & $1 / 2.5(18.2 \mathrm{~m})$ & $\begin{array}{l}\text { Shake table test } \\
(\text { Table size }: 20 \mathrm{~m} \times 15 \mathrm{~m})\end{array}$ & FY2008 \\
\hline
\end{tabular}

Table 2. Model conditions of element model test

\begin{tabular}{lllll}
\hline Test & Components & $\begin{array}{l}\text { Location } \\
\text { of trolley }\end{array}$ & $\begin{array}{l}\text { Weight } \\
\text { (Wire length) }\end{array}$ & Boundary condition \\
\hline $\begin{array}{l}\text { Test 1 } \\
\text { (See Fig. 1) }\end{array}$ & $\begin{array}{l}\text { Trolley, girders, } \\
\text { and saddles }\end{array}$ & $\begin{array}{l}\text { Center and end } \\
\text { of girder }\end{array}$ & None (None) & $\begin{array}{l}\text { Leap of girders was } \\
\text { constrained. }\end{array}$ \\
\hline $\begin{array}{l}\text { Test 2 } \\
\text { (See Fig. 5) }\end{array}$ & $\begin{array}{l}\text { Trolley, girders, } \\
\text { saddle, and } \\
\text { weight }\end{array}$ & Center of girder & $\begin{array}{l}555 / 1250 \mathrm{~kg} \\
(0.4 / 0.7 / 1.0 \mathrm{~m})\end{array}$ & $\begin{array}{l}\text { Slip of trolley and girders } \\
\text { was constrained. }\end{array}$ \\
\hline $\begin{array}{l}\text { Test series 3 } \\
\text { (See Fig. 9) }\end{array}$ & Wheel and rail & None & None (None) & None \\
\hline
\end{tabular}




\section{SUMMARY OF ELEMENT MODEL TEST}

\subsection{Element model test 1}

\subsubsection{Test setup}

Figure 1 shows the test setup of element model test 1 . The model was composed of two girders, a trolley positioned on them, and saddles connecting the girders. According to the similarity law, additional weight was installed in the model to adjust the acceleration effect which affects leap and slip behaviour. This test focused on the leap of a trolley mounted on flexible girders sliding on rails. The leap of the girders was constrained to simplify the leap behaviour. The effect of the trolley's location on the girders was also investigated as shown in Figs. 1a and 1b.

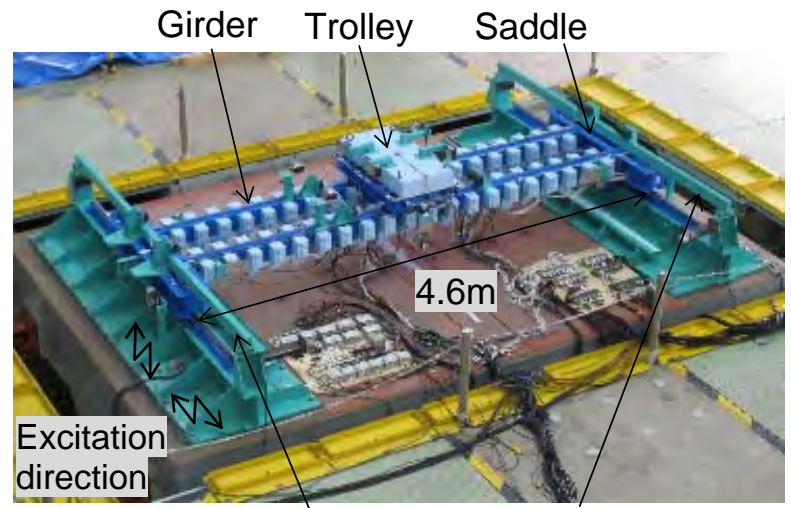

Beam to constrain leap of girder

a. Trolley is located at center of girders.

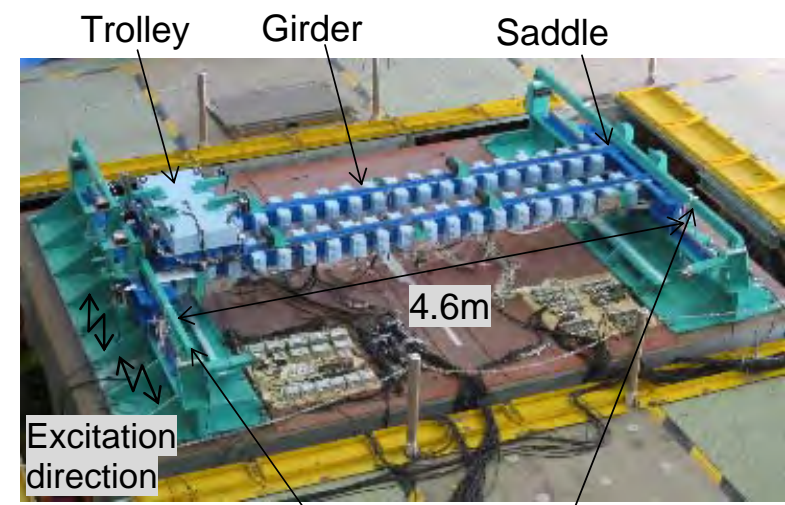

Beam to constrain leap of girder

b. Trolley is located at end of girders.

Figure 1. Test setup of element model test 1

\subsubsection{Excitation condition}

Artificial seismic waves used for seismic design of BWR plants were applied to travelling horizontal and vertical directions. Figure 2 shows an example of the time histories and response spectra of the waves. The time and frequency were modified to adjust the acceleration effect according to the similarity law.
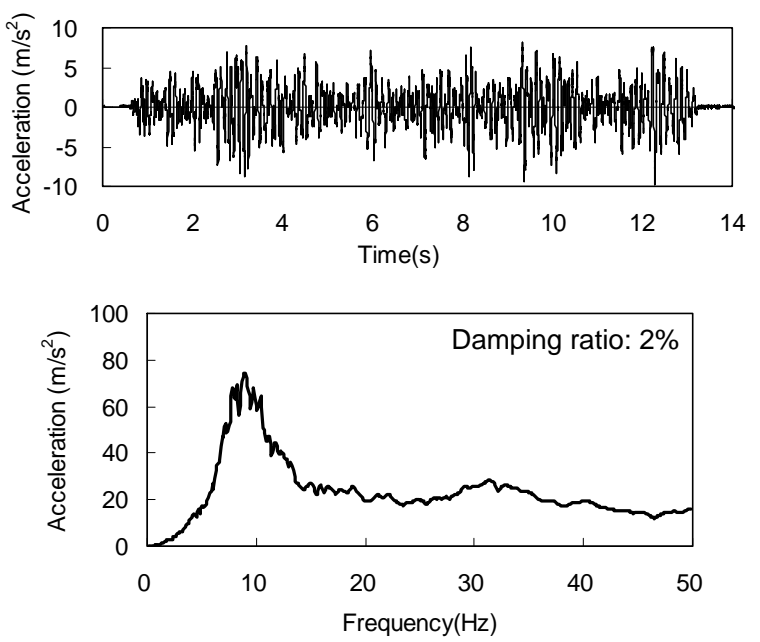

a. Horizontal excitation
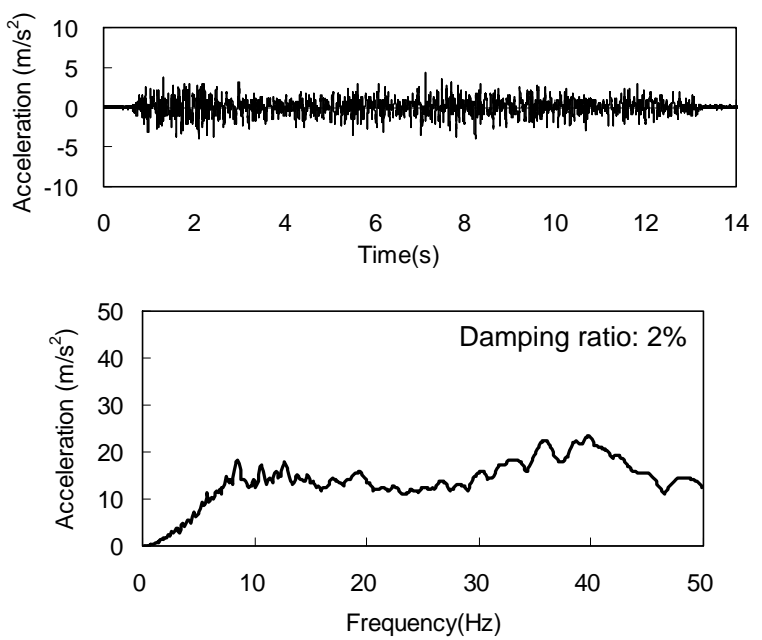

b. Vertical excitation

Figure 2. Example of time histories and response spectra of input waves for element model test 1 


\subsubsection{Test results}

Table 3 lists the test results of the 1st mode eigen frequency and damping ratio obtained from sweep tests. The eigen frequency increased by $20 \%$ when the trolley moved from the center to the end of the girders. The damping ratio increased slightly from $0.9 \%$ to $1.2 \%$.

The maximum upward displacement of the trolley and the maximum slip displacement of the girders are compared for different combinations of excitation directions in Fig. 3. Figure 3a indicates that horizontal excitation increases the upward displacement because this excitation amplifies the rocking behaviour of the trolley. Figure 3b indicates that vertical excitation decreases slip displacement. The change in friction force caused by vertical excitation might decrease slip caused by horizontal excitation.

The maximum upward displacement of the trolley and the slip displacement of the girders are compared for different locations of the trolley on the girders under horizontal and vertical excitations in Fig. 4. Figure 4a indicates that the maximum upward displacement decreases when the trolley moves from the center to the end of the girders because the response amplification decreases at the end of the girders. On the other hand, Fig. 4b indicates that the maximum slip displacement increases when the trolley moves to the end of the girder. The asymmetry of mass distribution in a crane might increase the slip of the girders.

Table 3. Sweep test results of element model test 1

\begin{tabular}{lll}
\hline Location of trolley & Eigen frequency & Damping ratio \\
\hline Center of girders & $9.4 \mathrm{~Hz}$ & $0.9 \%$ \\
\hline End of girders & $11.2 \mathrm{~Hz}$ & $1.2 \%$ \\
\hline
\end{tabular}

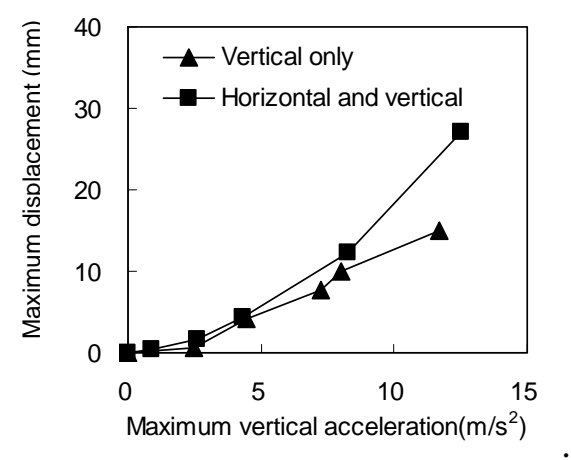

a. Upward displacement of trolley

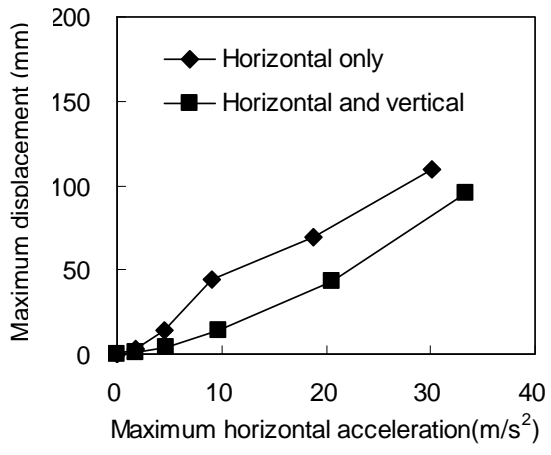

b. Slip displacement of girders

Figure 3. Comparison of maximum response for different combinations of excitation directions

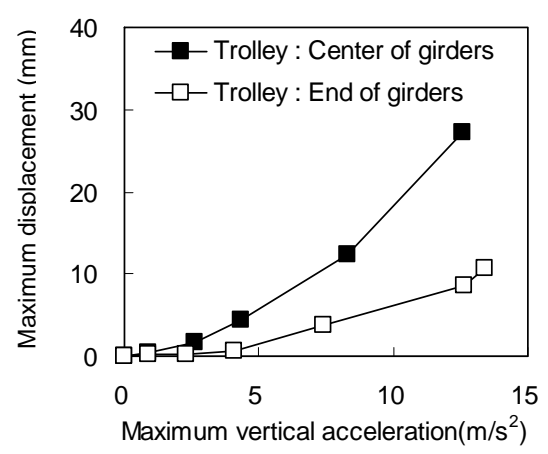

a. Upward displacement of trolley

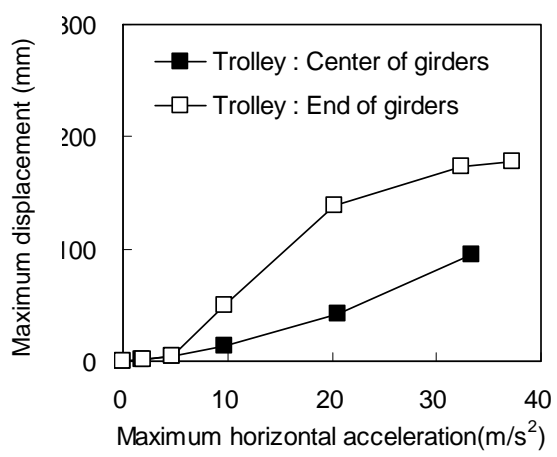

b. Slip displacement of girders

Figure 4. Comparison of maximum response for different trolley locations on girders 


\subsubsection{Test setup}

Figure 5 shows the test setup of element model test 2. The model composed of two girders, a trolley positioned on them, saddles and a carrying weight suspended from the trolley. According to the similarity law, additional weight was installed in the model to adjust the acceleration effect, which affects leap behaviour. Additional pieces of rope were also installed in case of the drop of the carrying weight. This test focused on the leap behaviour of the trolley, girders, carrying weight, and their interaction. The load sensors were installed instead of the wheels in the corners of the trolley and the girders to measure the reaction force. The weight amount and the wire length were changed to investigate the effect on the leap behaviour.
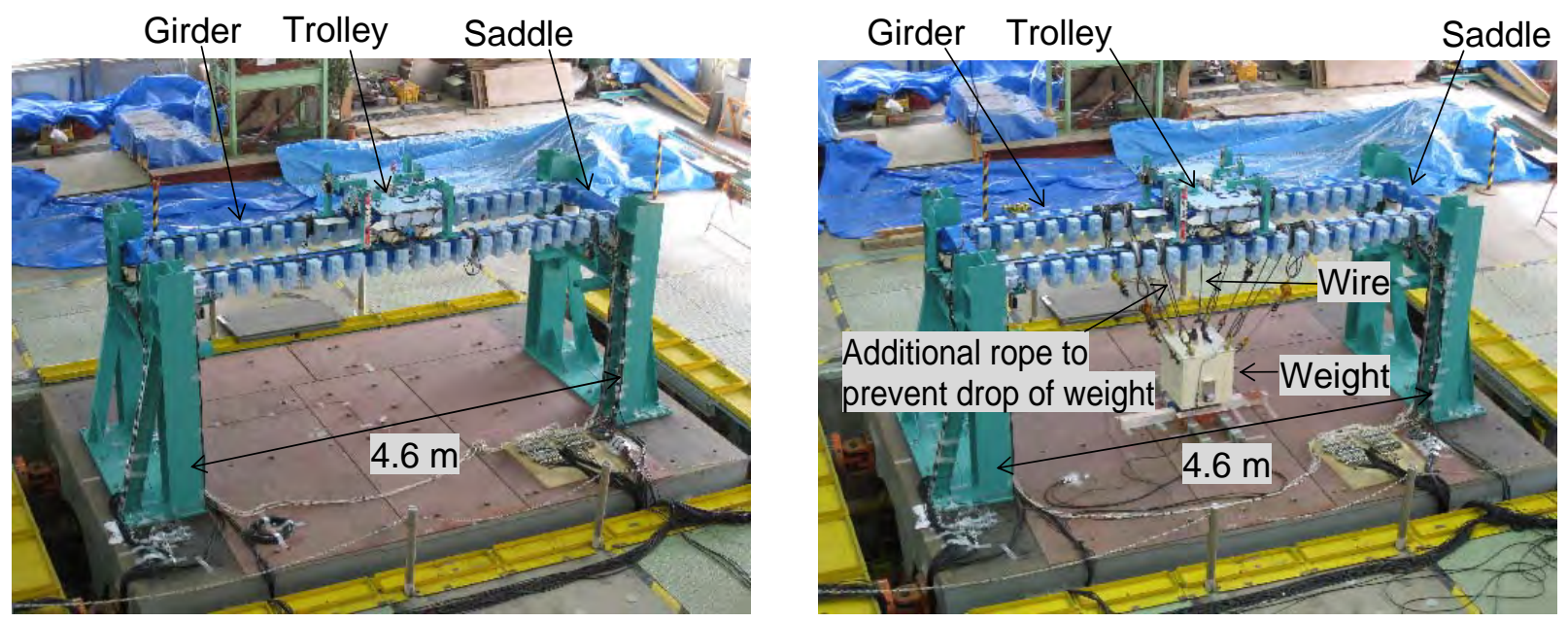

a. Without carrying weight

b. With carrying weight (Weight: $1250 \mathrm{~kg}$, Wire: $1.0 \mathrm{~m}$ )

Figure 5. Test setup of element model test 2

\subsubsection{Excitation condition}

The same artificial seismic waves of test 1 were only applied vertically. Figure 6 shows an example of the time history and response spectrum of the wave. The time and frequency were also modified to adjust the acceleration effect according to the similarity law.

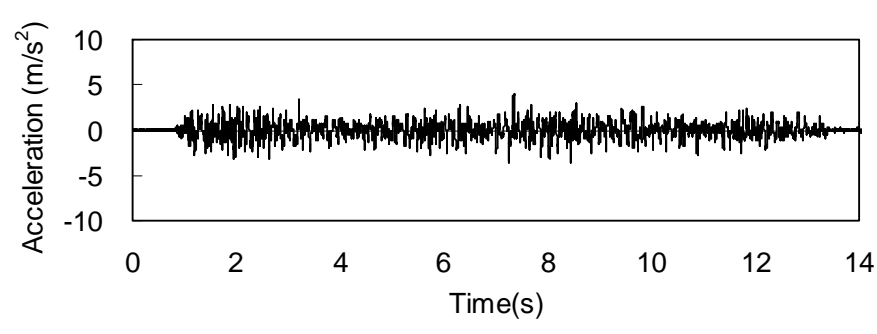

a. Time history

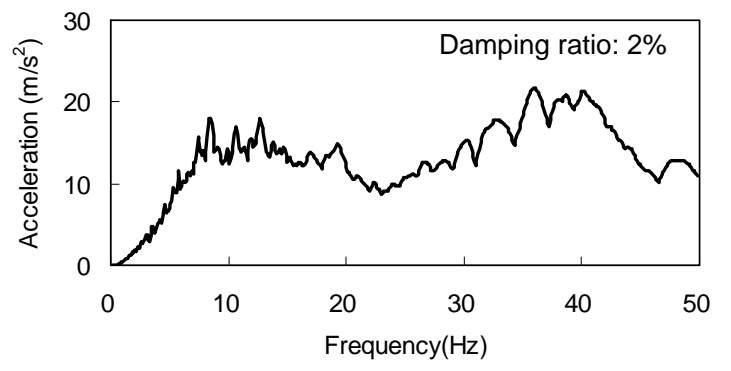

b. Response spectrum

Figure 6. Example of time history and response spectrum of input waves for element model test 2

\subsubsection{Test results}

Figure 7 shows the $1^{\text {st }}$ mode eigen frequency and the damping ratio obtained from sweep tests with different wire length. Figure $7 \mathrm{a}$ indicates that the eigen frequency was slightly lower as the wire length increased. Figure $7 \mathrm{~b}$ indicates that the damping ratio was higher as the wire length increased. The carrying weight and the wire may increase the damping of the overhead crane.

The maximum upward displacement of the trolley and girder, the maximum load in the positions corresponding to the wheels, the maximum wire load and the maximum axial strain on the girders are compared for different lengths of wire suspending the carrying weight $(1250 \mathrm{~kg})$ in Fig. 8. Figures 8a to 8d 
indicate that the carrying weight suspended by the wire tends to decrease the maximum displacement and load, and that the maximum displacement and load tend to decrease with increased wire length. Figures 8e and $8 \mathrm{f}$ indicate that the maximum wire load and axial strain have the same tendency as the other responses regarding the weight and the wire length. These figures also indicate that the maximum wire load and strain are almost proportional to the excitation level, even when the trolley or girders leap under vertical excitation as shown in Fig.8a and 8b. The effect of the impact, which occurs between the wheels and rails of after a leap of the trolley and girders, might be small for such wire load and strain. This fact suggests that it is not always necessary to consider the effect of the impact for these responses in seismic analysis.

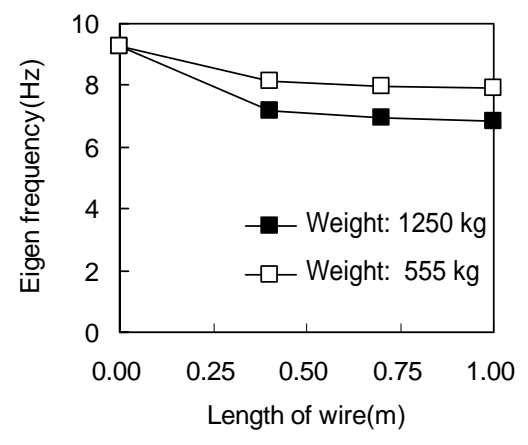

a. Eigen frequency

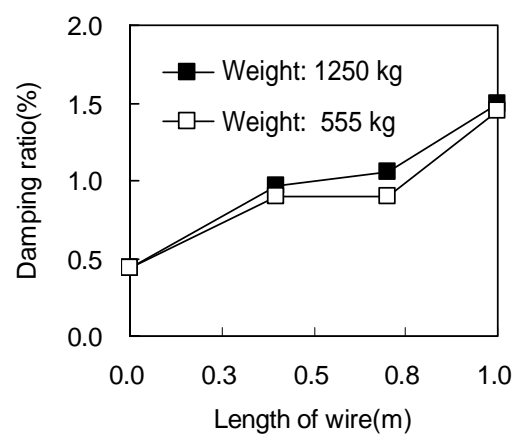

b. Damping ratio

Figure 7. Sweep test results of element model test 2

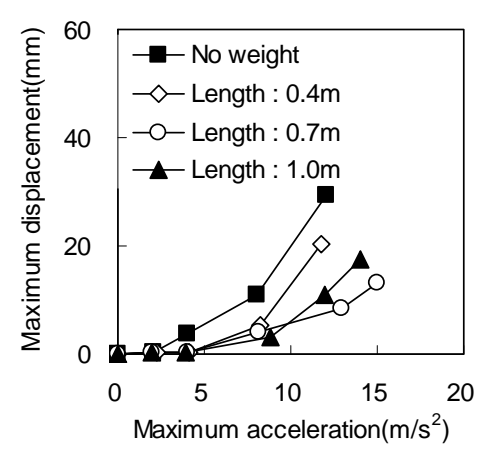

a. Upward displacement of trolley

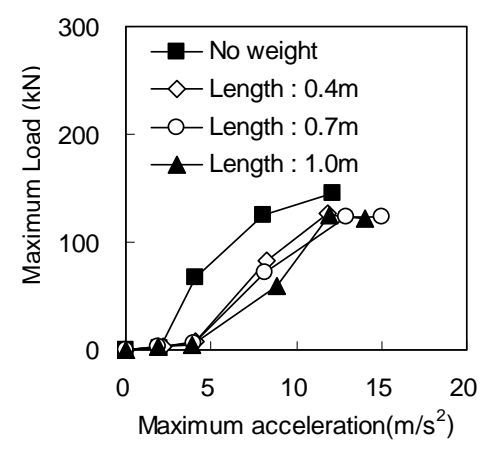

d. Vertical load of girder's corner

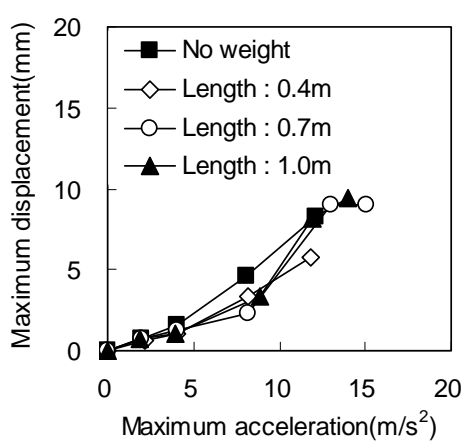

b. Upward displacement of girder

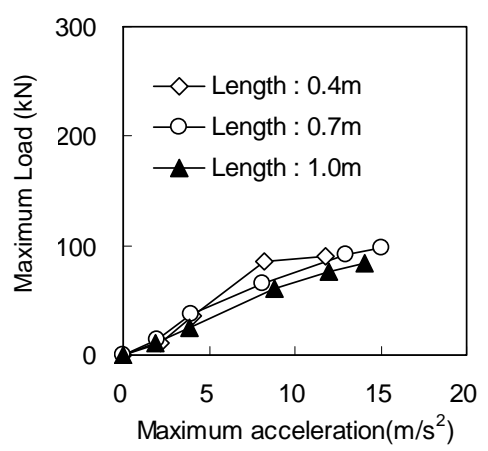

e. Tensile load of wire

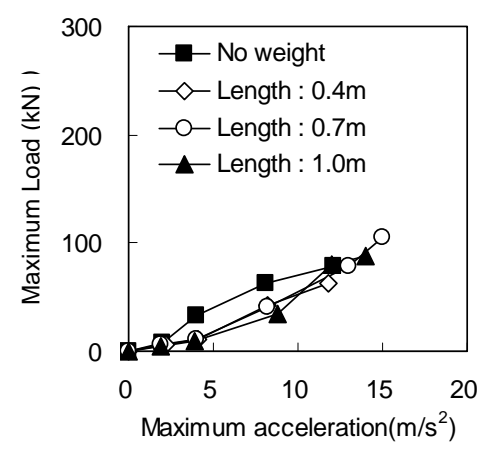

c. Vertical load of trolley's corner

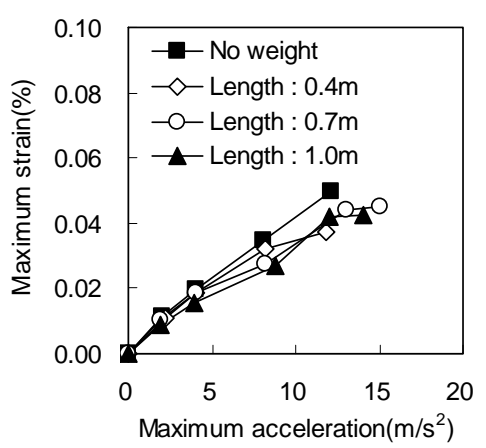

f. Axial strain of girder

Figure 8. Relationship between maximum response and excitation level obtained from element model tests 2

\subsection{Element model test 3}

\subsubsection{Test setup}

Figure 9 shows the test setup of element model test 3 . The wheel was lifted and released from a particular height toward a partial rail to obtain the coefficients of restitution between a wheel and rail. 


\subsubsection{Test results}

Figure 10 shows the coefficients of restitution obtained from the test. The coefficients ranged from 0.6 to 0.65 and were converted into damping ratio using the following relationship.

$$
e=\exp \left(-\frac{h \pi}{\sqrt{1-h^{2}}}\right)
$$

where $e$ is the coefficient of restitution and $h$ is the damping ratio. The minimum damping ratio was 0.12 , corresponding to the maximum coefficient obtained from the tests. The damping ratio was applied to the dashpot elements of the analysis model described in later section.

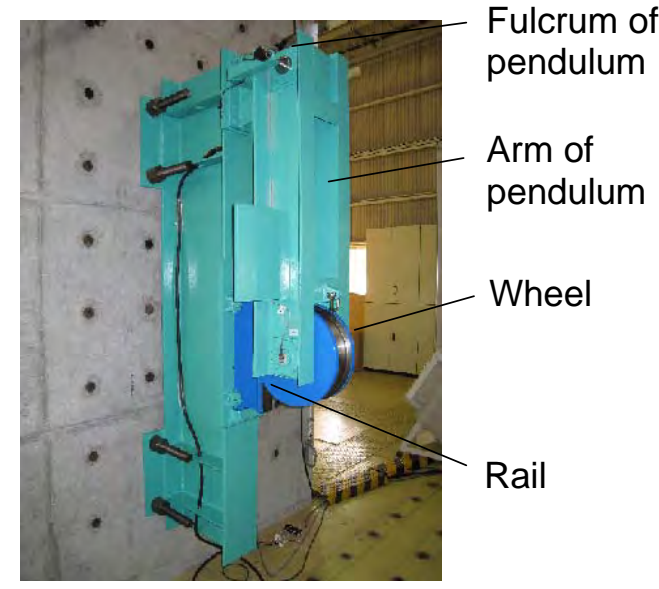

Figure 9. Test setup of element model test 3

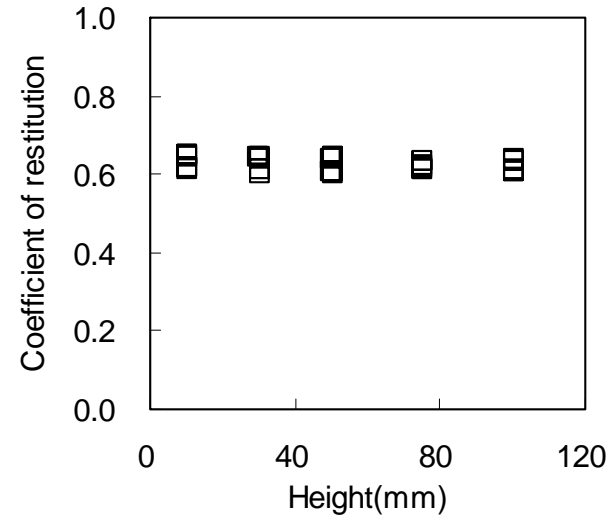

Figure 10. Coefficients of restitution obtained from test 3

\section{NUMERICAL SIMULATION}

Eigenvalue and nonlinear response analyses were performed to simulate the vibration and nonlinear behaviour for element model tests 1 and 2. A commercial finite element program, ABAQUS (Ver. 6.5.4), (ABAQUS is a trademark of ABAQUS, inc) was applied to this simulation.

\subsection{Analysis model}

Figure 11 shows the analysis models of the simulations. The models were composed of beam elements for girders and saddles, a rigid body element for the trolley, a combination of gap, spring, and dashpot elements to simulate the interaction between a wheel and the rail, and a truss element for the wire. The gap elements simulate a slip on a rail and contact between a wheel and the rail. The friction coefficient was set to 0.3. The spring elements simulate the contact stiffness between a wheel and the rail. The stiffness for element model test 1 was determined according to the Hertz contact theory using the dimension of wheels of a trolley and girders. The stiffness for element model test 2 was, however, determined on the basis of the parametric survey for a particular test case because the Hertz contact theory could not simulate the test for the model, where the load sensors were installed instead of wheels. The dashpot elements simulate damping caused by the contact between a wheel and the rail. Damping was determined from the coefficient of restitution obtained from element model test 3. The truss element had no stiffness for a compressive load to simulate wire behaviour as described in ASME NOG (2004).

\subsection{Nonlinear Analysis}

Table 4 lists comparisons between test and analysis results of the 1st mode eigen frequency. The difference between the test and analysis results was at most 3\%, and the analysis simulated the test results well.

Tables 5 and 6 list the comparison of the maximum responses between test and analysis results in the highest excitation level for element model tests 1 and 2. The difference in the maximum upward displacement between test and analysis results was at most 20\%. However, the difference in the maximum load between test and analysis results ranged from $30 \%$ to $50 \%$, and the analyses tend to overestimate the 
load compared to the test results. The peak in the load history might change easily because the sharp pulses are caused by the impact after the leap of the trolley or girders. Besides, the maximum load was strongly dependent on the contact stiffness of the spring elements. These two factors might cause the difference between test and analysis results. On the other hand, the analysis underestimated the maximum slip displacement compared to the test results. The analysis results of the slip are strongly dependent on friction, and further investigation might, therefore, be required to evaluate slip behaviour.

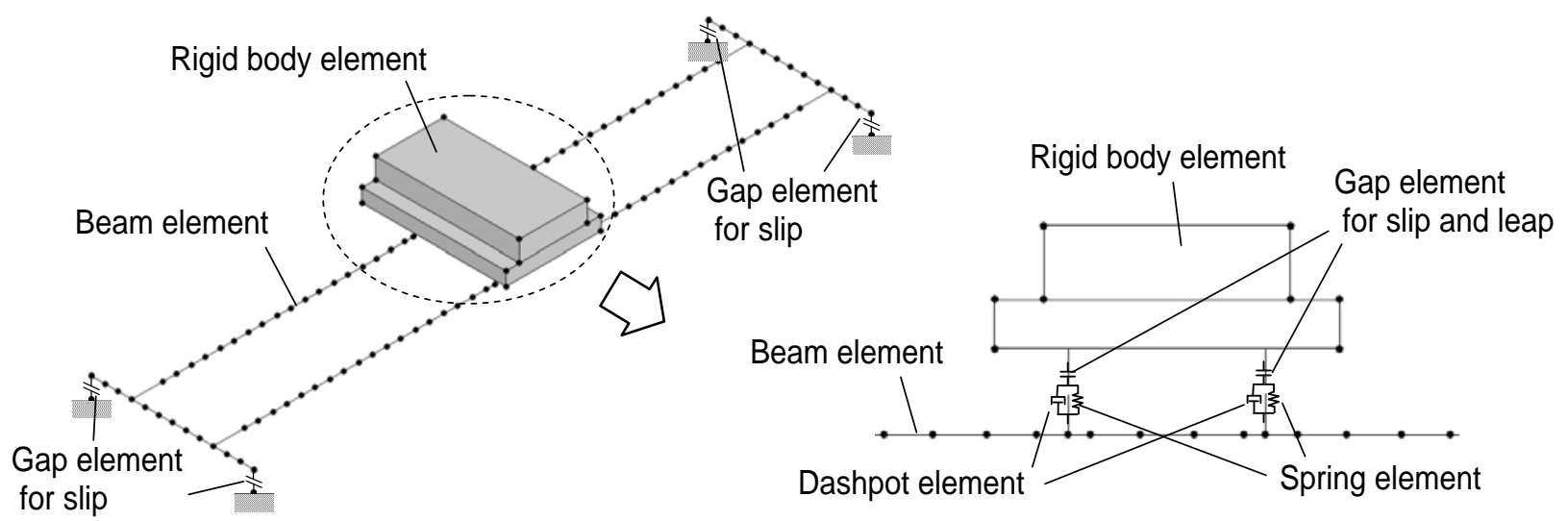

a. Element model test 1

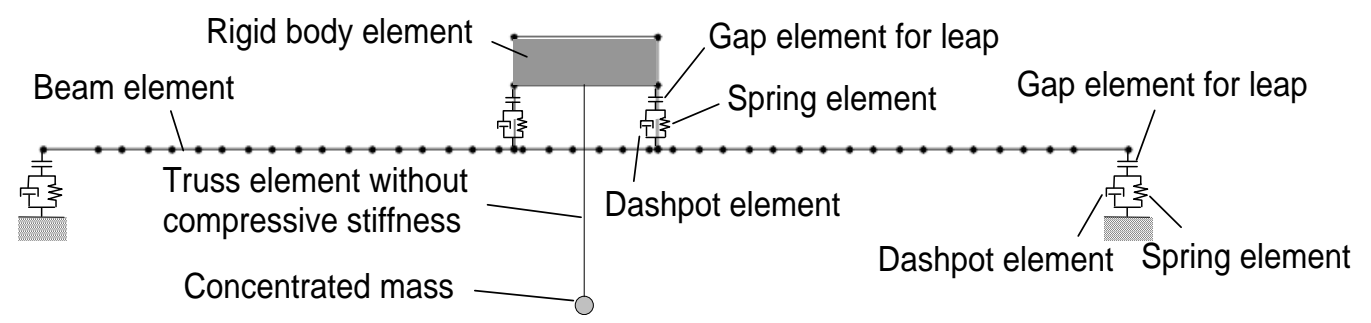

b. Element model test 2

Figure 11. Analysis models for simulation of element model test

Table 4. Comparison of eigen frequency between test and analysis results

\begin{tabular}{llll}
\hline Test series & Length of wire & Test & Analysis \\
\hline Element model test 1 & None & $9.4 \mathrm{~Hz}$ & $9.2 \mathrm{~Hz}$ \\
\hline Element model test 2 & $0.0 \mathrm{~m}$ (No weight) & $9.2 \mathrm{~Hz}$ & $9.1 \mathrm{~Hz}$ \\
\cline { 2 - 4 } & $0.4 \mathrm{~m}$ & $7.2 \mathrm{~Hz}$ & $7.1 \mathrm{~Hz}$ \\
\cline { 2 - 4 } & $0.7 \mathrm{~m}$ & $7.0 \mathrm{~Hz}$ & $7.0 \mathrm{~Hz}$ \\
\cline { 2 - 4 } & $1.2 \mathrm{~m}$ & $6.9 \mathrm{~Hz}$ & $6.9 \mathrm{~Hz}$ \\
\hline
\end{tabular}

Table 5. Comparison of maximum responses between test and analysis results in element model test 1

\begin{tabular}{llll}
\hline Response & Test & Analysis & Analysis/Test \\
\hline Horizontal acceleration on shake table & $33.4 \mathrm{~m} / \mathrm{s}^{2}$ & & - \\
Vertical acceleration on shake table & $12.6 \mathrm{~m} / \mathrm{s}^{2}$ & & \\
\hline Upward displacement of trolley & $30.6 \mathrm{~mm}$ & $36.8 \mathrm{~mm}$ & 1.20 \\
\hline Slip displacement of girders & $109.1 \mathrm{~mm}$ & $29.7 \mathrm{~mm}$ & 0.27 \\
\hline
\end{tabular}


Table 6. Comparison of maximum responses between test and analysis results in element model test 2 (Wire length: $1.0 \mathrm{~m}$, Weight: $550 \mathrm{~kg}$ )

\begin{tabular}{llll}
\hline Response & Test & Analysis & Analysis/Test \\
\hline Vertical acceleration on shake table & $11.1 \mathrm{~m} / \mathrm{s}^{2}$ & - & - \\
\hline Upward displacement of trolley & $18.7 \mathrm{~mm}$ & $16.0 \mathrm{~mm}$ & 0.86 \\
\hline Upward displacement of girders & $7.5 \mathrm{~mm}$ & $8.3 \mathrm{~mm}$ & 1.11 \\
\hline Load in the corner of trolley & $170.1 \mathrm{kN}$ & $221.4 \mathrm{kN}$ & 1.30 \\
\hline Load in the corner of girders & $89.4 \mathrm{kN}$ & $138.4 \mathrm{kN}$ & 1.55 \\
\hline Load of wire & $61.4 \mathrm{kN}$ & $83.3 \mathrm{kN}$ & 1.36 \\
\hline
\end{tabular}

\section{CONCLUSION}

The results of the element model test in the JNES program were summarized. The test was composed of two shake table tests and an impact test, and nonlinear behaviour under vertical excitation was a focus of these tests. A summary of the test results is as follows. (1) Horizontal excitation tends to increase the upward displacement of a trolley due to rocking behaviour, and vertical excitation tends to decrease the slip behaviour of girders when friction force is changed by vertical excitation. (2) The upward displacement of a trolley decreases when it moves to the end of the girders because response amplification decreases, while the slip of the girders increases. (3) A carrying weight suspended by a wire tends to decrease the maximum displacement, load and strain. The wire load and the axial strain of the girders are almost proportional to the excitation level, and this fact suggests that it is not always necessary to consider the effect of the impact for such responses in seismic analysis. (4) Coefficients of restitution between a wheel and the rail was investigated for a simulation model, and a corresponding damping ratio of 0.12 was obtained.

Simulation analyses were conducted for simulation of the shake table tests, and the results were compared with the test results and discussed. The difference in the maximum upward displacement between the test and analysis results was at most 20\%. However, the analyses overestimated the load, and underestimated the slip displacement. The difference in the load might come from the effect of sharp pulses at impact and the dependence of contact stiffness on the load. Slip is strongly dependent on friction, and further investigation might, therefore, be required. These analysis-modelling methods will be verified further using a 1/2.5-scale model test of the next test series in the JNES program.

\section{REFERENCES}

ABAQUS, Inc., 2003, ABAQUS Analysis User’s Manual, Version 6.4.

ASME. 2004. Rules for Construction of overhead and gantry cranes(top running bridge, multiple girder). ASME NOG-1-2004.

Komori, A., Ueki, T., Hirata, M. Hoshii, T.and Kashiwazaki, A. 1989. Seismic behaviour with sliding of overhead travelling crane. Thermal and nuclear power engineering society. Vol. 40:6. P. 673-680.

Nuclear Safety Commission of Japan. 2006. The regulatory guide for reviewing seismic design of nuclear power reactor facilities.

Otani, A., Yoshitomi, T., Komori, O. Nagashima, K.and Suzuki, J. 1999. Vertical seismic response of overhead crane. Transactions of the 15th international conference on structural mechanics in reactor technology(SMiRT-15). Vol. K11/5. P. IX-121-IX-128. 